\title{
Discordance of P53 Mutations of Synchronous Colorectal Carcinomas
}

\author{
Kouichi Eguchi, M.D., Takashi Yao, M.D., Tatsuo Konomoto, M.D., Kenshi Hayashi, Ph.D.,
} Masatoshi Fujishima, M.D., Masazumi Tsuneyoshi, M.D.

Department of Anatomic Pathology, Pathological Sciences, Graduate School of Medical Sciences (KE, TY, TK, MT); Division of Genome Analysis, Institute of Genetic Information (KH); and Second Department of Internal Medicine, Faculty of Medicine (MF), Kyushu University, Fukuoka, Japan

It is unclear whether synchronous multiple tumors arise from multicentric or monoclonal origins. To verify the multicentric origin of synchronous colorectal carcinomas at a genetic level, immunohistochemical and molecular techniques were used to determine the p53 alterations in individual lesions of synchronous colorectal carcinomas. This study was based on a total of 32 colorectal tumors from 16 patients. Twenty-one of the $32(66 \%)$ advanced tumors examined had positive staining for p53. Single-strand conformation polymorphism and polymerase chain reaction direct sequencing were carried out for exons 5 to 8 of p53. All cases had p53 mutations in one or more tumors of synchronous lesions. In nine patients in this series, individual lesions were found to carry a different mutated codon of the $p 53$ gene. In the other seven patients, a $p 53$ mutation was found in one tumor but not in another. These results indicate discordance of the mutation pattern of $p 53$ in individual lesions of multiple colorectal carcinomas and support the idea that most synchronous colorectal carcinomas are genetically distinguishable and are multicentric in origin. We also confirmed the high frequency of p53 mutations in left-sided $(71 \%)$ and rectal $(91 \%)$ carcinomas, rather than right-sided $(43 \% ; P=.04)$ carcinomas, suggesting that the molecular mechanism of synchronous colorectal carcinomas might differ between right- and left-sided tumors in the same patient.

Copyright () 2000 by The United States and Canadian Academy of Pathology, Inc.

VOL. 13, NO. 2, P. 131, 2000 Printed in the U.S.A

Date of acceptance: September 17, 1999.

Address reprint requests to: Masazumi Tsuneyoshi, M.D., Department of Anatomic Pathology, Pathological Sciences, Graduate School of Medical Sciences, Kyushu University 60, 3-1-1 Maidashi, Higashi-ku, Fukuoka 812-8582, Japan; e-mail: masazumi@surgpath.med.kyushu-u.ac.jp; fax: 81-92-642-5968.
KEY WORDS: P53, Single-strand conformation polymorphism, Synchronous colorectal carcinomas.

Mod Pathol 2000;13(2):131-139

The incidence of two or more primary colorectal carcinomas has been estimated to be 2 to $11 \%$ of all carcinomas in the colon and rectum. In 1957, Moertel and his colleagues (1) proposed histologic criteria for multiple colorectal carcinomas. However, it has been difficult to determine whether individual lesions in synchronous colorectal carcinomas arise from multicentric or monoclonal origins using conventional clinical and morphologic studies, because such lesions frequently show similar morphologic features both macroscopically and microscopically. Molecular biologic techniques have made it possible to evaluate multicentricity (i.e., to exclude metastases) at a genetic level. Greenblatt $e t$ al. (2) also reported that the analysis of substitution mutations can provide clues to the cause of these diverse lesions. Many investigators have attempted to determine the cause of multiple tumors in different organs using several molecular techniques. In the upper aerodigestive tract $(3,4)$, lung (5), stomach (6), and liver (7), multiple carcinomas have been alleged to be multicentric in origin. Conversely, investigators have claimed that multiple tumors in the bladder $(8,9)$, gynecologic organs (10-12), and breast (13) have the same clonal origin rather than multicentric. Moreover, some investigators have reported that multiple tumors in the urothelial organs and liver can have either a common or an independent origin (14-16).

The frequency of synchronous lesion generally is recognized to be much greater in patients who also have ulcerative colitis than in the general population (17). With regard to the synchronous colorectal carcinomas in patients without inflammatory bowel disease, some authors have reported the 
causative characteristics. On the basis of an analysis of p53 and K-ras mutations, Koness et al. (18) concluded that the great majority of synchronous colonic adenocarcinomas arose as independent neoplasms. In contrast, Schwartz et al. (19), on the basis of an analysis of nuclear DNA content, suggested that such lesions arose as transmural metastases from an initial single lesion.

Mutation of the $p 53$ gene is the most common genetic alteration observed in many kinds of human neoplasms. As a molecular marker, $p 53$ is considered to be helpful for differentiating between synchronous colorectal carcinomas of multicentric and monoclonal origin, because it is believed to be the most prevalent genetic alteration. The purpose of the current study was to classify the characteristics and to verify the possibility of a multicentric origin of synchronous colorectal carcinomas at a genetic level focusing on $p 53$ alterations. We used immunohistochemical and molecular techniques to determine the mutation pattern of $p 53$ in individual lesions of synchronous colorectal carcinomas.

\section{MATERIALS AND METHODS}

\section{Samples}

The clinicopathologic data are summarized in Table 1. Thirty-two colorectal carcinomas (formalinfixed, paraffin-embedded tissues) were obtained from 16 patients who had undergone surgical resection and been diagnosed with synchronous colorectal carcinomas at the Department of Anatomic Pathology, Kyushu University, Pathological Sciences, Japan. Three patients (Patients 16, 17, and 20) had earlystage carcinomas in addition to advanced carcinomas, and these additional lesions were excluded from this study. All of the patients in this study initially were operated on at the Kyushu University Hospital or related hospitals. None of the cases received preoperative therapy, such as chemotherapy. The patients included 12 men and 4 women, ranging in age from 55 to 83 years (average, 66 years). Synchronous carcinomas met the criteria established by Moertel $e t$ al. (1). None of the patients had inflammatory bowel disease or familial polyposis syndrome. Our cases did not include the patients with hereditary nonpolyposis

TABLE 1. Clinicopathological and P53 Status of Synchronous Colorectal Carcinomas

\begin{tabular}{|c|c|c|c|c|c|c|c|c|c|c|}
\hline $\begin{array}{c}\text { Patient } \\
\text { No. }\end{array}$ & Age & Sex & $\begin{array}{c}\text { Tumor } \\
\text { No. }\end{array}$ & $\begin{array}{c}\text { Dukes' } \\
\text { Stage }\end{array}$ & Location & Grade $^{a}$ & $\begin{array}{c}\text { Adenoma } \\
\text { Component }\end{array}$ & $\begin{array}{c}\text { Depth } \\
\text { of } \\
\text { Invasion }\end{array}$ & $\begin{array}{c}\text { P53 } \\
\text { Mutation }\end{array}$ & IHC \\
\hline \multirow[t]{2}{*}{3} & 72 & $\mathrm{~F}$ & $\mathrm{~T} 1$ & NI & $\mathrm{D}$ & $\mathrm{L}$ & - & ss & + & 0 \\
\hline & & & $\mathrm{T} 2$ & & $\mathrm{~T}$ & $\mathrm{~L}$ & - & ss & + & $2+$ \\
\hline \multirow[t]{2}{*}{6} & 59 & $\mathrm{M}$ & $\mathrm{T} 1$ & $\mathrm{C}$ & $\mathrm{R}$ & $\mathrm{L}$ & + & ss & none & $1+$ \\
\hline & & & $\mathrm{T} 2$ & & $\mathrm{R}$ & $\mathrm{H}$ & - & ss & + & $2+$ \\
\hline \multirow[t]{2}{*}{7} & 63 & $\mathrm{M}$ & $\mathrm{T} 1$ & $\mathrm{C}$ & $\mathrm{S}$ & $\mathrm{L}$ & + & ss & + & $2+$ \\
\hline & & & $\mathrm{T} 2$ & & $\mathrm{Ce}$ & $\mathrm{L}$ & + & ss & none & 0 \\
\hline \multirow[t]{2}{*}{9} & 58 & $\mathrm{~F}$ & $\mathrm{~T} 1$ & B & $\mathrm{R}$ & $\mathrm{L}$ & - & ss & + & $3+$ \\
\hline & & & $\mathrm{T} 2$ & & $\mathrm{R}$ & $\mathrm{L}$ & - & ss & silent & $3+$ \\
\hline \multirow[t]{2}{*}{13} & 83 & M & $\mathrm{T} 1$ & $\mathrm{C}$ & S & $\mathrm{L}$ & + & ss & + & 0 \\
\hline & & & $\mathrm{T} 2$ & & S & $\mathrm{L}$ & - & ss & + & $3+$ \\
\hline \multirow[t]{2}{*}{14} & 55 & M & $\mathrm{T} 1$ & $\mathrm{C}$ & $\mathrm{S}$ & $\mathrm{L}$ & - & ss & + & $2+$ \\
\hline & & & $\mathrm{T} 2$ & & $\mathrm{~S}$ & $\mathrm{~L}$ & - & ss & intron & $1+$ \\
\hline \multirow[t]{2}{*}{15} & 62 & M & $\mathrm{T} 1$ & B & $\mathrm{R}$ & $\mathrm{L}$ & - & ss & + & $3+$ \\
\hline & & & $\mathrm{T} 2$ & & $\mathrm{R}$ & $\mathrm{L}$ & - & ss & + & $3+$ \\
\hline \multirow[t]{2}{*}{16} & 65 & M & $\mathrm{T} 1$ & $\mathrm{C}$ & $\mathrm{D}$ & $\mathrm{H}$ & - & ss & none & 0 \\
\hline & & & $\mathrm{T} 2$ & & $\mathrm{~T}$ & $\mathrm{~L}$ & - & ss & + & 0 \\
\hline \multirow[t]{2}{*}{17} & 80 & $\mathrm{~F}$ & $\mathrm{~T} 1$ & $\mathrm{C}$ & $\mathrm{S}$ & $\mathrm{L}$ & - & ss & + & $3+$ \\
\hline & & & $\mathrm{T} 2$ & & S & $\mathrm{L}$ & - & ss & + & $3+$ \\
\hline \multirow[t]{2}{*}{19} & 64 & M & $\mathrm{T} 1$ & $\mathrm{C}$ & $S$ & $\mathrm{~L}$ & - & ss & + & $3+$ \\
\hline & & & $\mathrm{T} 2$ & & $\mathrm{D}$ & $\mathrm{L}$ & - & ss & + & $3+$ \\
\hline \multirow[t]{2}{*}{20} & 62 & $\mathrm{M}$ & $\mathrm{T} 1$ & $\mathrm{C}$ & A & $\mathrm{H}$ & - & ss & none & 0 \\
\hline & & & $\mathrm{T} 2$ & & $\mathrm{R}$ & $\mathrm{L}$ & - & ss & + & $3+$ \\
\hline \multirow[t]{2}{*}{21} & 64 & $\mathrm{~F}$ & $\mathrm{~T} 1$ & B & A & $\mathrm{L}$ & + & ss & none & 0 \\
\hline & & & $\mathrm{T} 2$ & & $S$ & $\mathrm{~L}$ & - & ss & + & $1+$ \\
\hline \multirow[t]{2}{*}{22} & 81 & $\mathrm{M}$ & $\mathrm{T} 1$ & $\mathrm{C}$ & $\mathrm{R}$ & $\mathrm{L}$ & - & ss & + & $3+$ \\
\hline & & & $\mathrm{T} 2$ & & $S$ & $\mathrm{H}$ & - & ss & none & $3+$ \\
\hline \multirow[t]{2}{*}{23} & 74 & M & $\mathrm{T} 1$ & $\mathrm{C}$ & $\mathrm{R}$ & $\mathrm{L}$ & - & ss & + & $1+$ \\
\hline & & & $\mathrm{T} 2$ & & $\mathrm{~S}$ & $\mathrm{~L}$ & - & ss & + & 0 \\
\hline \multirow[t]{2}{*}{24} & 65 & $\mathrm{M}$ & $\mathrm{T} 1$ & $\mathrm{C}$ & $\mathrm{R}$ & $\mathrm{L}$ & - & ss & + & $1+$ \\
\hline & & & $\mathrm{T} 2$ & & $\mathrm{R}$ & $\mathrm{L}$ & - & ss & + & 0 \\
\hline \multirow[t]{2}{*}{25} & 55 & M & $\mathrm{T} 1$ & B & $\mathrm{T}$ & L\# & - & ss & none & 0 \\
\hline & & & $\mathrm{T} 2$ & & $\mathrm{~T}$ & $\mathrm{~L}$ & - & $\mathrm{mp}$ & + & 0 \\
\hline
\end{tabular}

IHC, immunohistochemistry; F, female; M, male; NI, not informative; C, tumors with lymph node metastases; B, tumors extending to the wall; D, descending colon; T, transverse colon; R, rectum; S, sigmoid colon; Ce, cecum; A, ascending colon; L, low grade; H, high grade; -, without areas of adenoma; +, with areas of adenoma; ss, subserosa; mp, muscularis propria; intron, intronic point; 0 , negative tumors; $1+$, low expression ( 1 to $10 \%$ immunoreactive tumor cells); $2+$, moderate expression (10 to $50 \%$ immunoreactive tumor cells); $3+$, high expression ( 50 to $100 \%$ immunoreactive tumor cells); \#, mucinous carcinoma.

${ }^{a}$ According to the method of Jass. 
colorectal cancer, which is qualified by the minimum criteria in Amsterdam in 1990 (20), as far as we investigated. All of the specimens were embedded in paraffin after fixation in $10 \%$ formalin. Histologic sections taken for routine pathologic examination were evaluated and classified according to the World Health Organization classification (21), and staging was done according to the Turnbull modification of Dukes' classification (22). The larger tumor in each case was named $\mathrm{T} 1$. The data were statistically analyzed using Fisher's exact test.

\section{P53 Immunohistochemistry}

In all 32 tumor tissues from the 16 patients, immunohistochemical staining of p53 protein was performed. Four-micron-thick sections were cut, deparaffinized in xylene, and hydrated in descending dilutions of ethanol. After heating in phosphatebuffered saline ( $\mathrm{pH}$ 7.2) for $10 \mathrm{~min}$ for antigen retrieval, endogenous peroxidase activity was blocked by 30 min of incubation with $0.3 \%$ hydrogen peroxide. All of the sections were incubated with the primary antibody PAb1801 (dilution 1/100; Oncogene Science, Cambridge, MA) overnight at $4^{\circ} \mathrm{C}$. The subsequent development of antibody-bridge labeling was made by the streptavidin-biotinperoxidase method (Histofine SAB-PO Kit; Nichirei, Tokyo, Japan) with hematoxylin counterstaining. Appropriate positive and negative controls were included. Immunoreactivity for p53 protein was evaluated by the distribution pattern of positive nuclei as follows: 0 , negative tumors; $1+$, low expression (1 to $10 \%$ immunoreactive tumor cells); $2+$, moderate expression (10 to 50\%); $3+$, high expression (50 to $100 \%)$.

\section{DNA Preparation}

DNA was extracted from the paraffin-embedded tissue samples as described by Goelz et al. (23) with slight modifications. Briefly, sections (approximately $2 \mathrm{~cm} \times 2 \mathrm{~cm} \times 10 \mu \mathrm{m}$ ) dissected with a scalpel were deparaffinized with xylene, hydrated with ethanol, and digested in proteinase $\mathrm{K}$ solution $(0.1$ $\mathrm{mg} / \mathrm{mL}$ proteinase $\mathrm{K}, 100 \mathrm{~mm} \mathrm{NaCl}, 10 \mathrm{~mm}$ Tris-Cl, 25 mm EDTA, and $0.5 \%$ sodium dodecyl sulfate) for 48 to $72 \mathrm{~h}$ at $37^{\circ} \mathrm{C}$. After phenol/chloroform extraction, DNA was precipitated with ethanol and redissolved in $0.1 \times$ TE buffer ( $10 \mathrm{~mm}$ Tris, $1 \mathrm{~mm}$ EDTA). The concentration of the DNA solutions was determined by spectrophotometry and adjusted to 50 $\mathrm{ng} / \mu \mathrm{l}$. In all cases, DNA extracted from normal tissue of the same patients was used as a normal control.

\section{Oligonucleotide Primers}

Oligonucleotides for exons 5 and 6 of the $p 53$ gene were obtained commercially (Clonetech, Palo
Alto, CA). Their nucleotide sequences were as follows: PU5 (5'-CTCTTCCTGCAGTACTCCCCTGC3'), PD5 (5'-GCCCAGCTGCTCACCATCGCTA-3'), PU6 (5' -GATTGCTCTTAGGTCTGGCCC-CTC-3'), PD6 (5' -GGCCACTGACAACCACCCTTAACC-3'); primers P71 (5'-GCTTGCCACAGGTCTCCCCAAG$\left.3^{\prime}\right)$ and P72 (5'-GTCAGGAGCCACTTGCCACCCTG$\left.3^{\prime}\right)$. P81 (5'-TGGTAATCTACTGGGACGGA-3') and P82 (5'-GCTTAGTGCTCCCTGGGGGC-3') were noted to amplify exons 7 and 8.

\section{Polymerase Chain Reaction Amplification}

Genomic DNA was amplified by the polymerase chain reaction (PCR) in two steps (24). The first reaction mixtures $(5 \mu \mathrm{l})$ contained $50 \mathrm{ng}$ DNA, 1 pmol of each primer, $50 \mathrm{~mm} \mathrm{KCl,} 10 \mathrm{~mm}$ Tris- $\mathrm{HCl}$ (pH 8.3), $2 \mathrm{~mm} \mathrm{MgCl2,} \mathrm{dNTPs} \mathrm{at} 25 \mathrm{~mm}$ each, and 0.25 units of AmpliTaq DNA Polymerase (PerkinElmer, Branchburg, NJ). Forty cycles of the reaction at $95^{\circ} \mathrm{C}$ for $1 \mathrm{~min}, 66^{\circ} \mathrm{C}$ for $1 \mathrm{~min}$, and $72^{\circ} \mathrm{C}$ for 2 min were performed in an automatic programmable thermal cycler (Gene Amp PCR System 9600; Perkin-Elmer Cetus, Norwalk, CT). The PCR products were electrophoresed on $2 \%$ agarose gel and stained with ethidium bromide. Bands that showed the proper length were cut, and the DNAs were eluted from the gel using a filter cartridge (SUPREC01; Takara, Kyoto, Japan). The labeling reaction was then carried out using $1 \mu \mathrm{l}$ of the eluted PCR products with $2 \mu \mathrm{Ci} \alpha 32$-PdCTP for 10 cycles under the same conditions as described above. After Klenow treatment was performed, $40 \mu \mathrm{l}$ of formamide dye (95\% formamide, $20 \mathrm{~mm}$ EDTA, 0.05\% bromophenol blue, and $0.05 \%$ xylene cyanol) was added to the reactions.

\section{Single-Strand Conformation Polymorphism Analysis}

Single-strand conformation polymorphism (SSCP) analysis was performed as previously described $(25,26)$. Electrophoresis was carried out under four different conditions as follows: Samples were denatured at $80^{\circ} \mathrm{C}$ for $5 \mathrm{~min}$ and loaded onto nondenaturing $5 \%$ polyacrylamide gel with or without $5 \%$ glycerol; electrophoresis was performed at $40 \mathrm{~W}$ for 90 to $150 \mathrm{~min}$ at $15^{\circ} \mathrm{C}$ and $25^{\circ} \mathrm{C}$, using a water-jacketed electrophoretic apparatus; gels were dried and exposed to X-ray films (XAR-5; Kodak, Rochester, NY) for 12 to $24 \mathrm{~h}$ at room temperature.

\section{Direct DNA Sequencing}

Abnormal bands detected by SSCP analysis were eluted from the gel and reamplified by PCR as described previously (26). The products were sequenced with $5^{\prime}$-and $3^{\prime}-{ }^{32} \mathrm{P}$-labeled primers using a Thermo Sequenase cycle sequencing kit (Amer- 


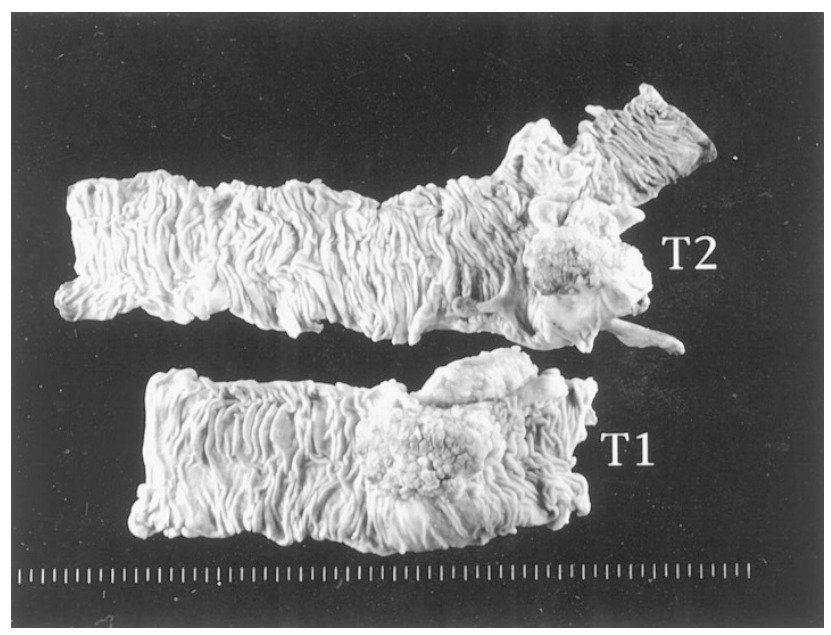

FIGURE 1. Patient 7. Two advanced carcinomas in the sigmoid colon (T1, lower) and the cecum (T2, upper).

sham, LIFE SCIENCE, Cleveland, OH). The primers used in the PCR-SSCP analysis served as sequencing primers. The conditions were according to the instructions of the manufacturer. Samples were loaded onto denaturing $6 \%$ urea gel and electrophoresed. Gels were then exposed to X-ray films (RX; Fuji, Kanagawa, Japan) and developed. When a mutation was found, PCR-SSCP analysis was repeated using the original DNA sample to exclude the possibility of PCR-induced DNA sequence changes. Moreover, when mutations at multiple sites on the p53 genome or the results of immunoreactivity and sequence analysis conflicted, new DNA samples were extracted from the sequential sections of the tumor paraffin block. PCR-SSCP analysis was then repeated to eliminate any possibility of identical mutations resulting from DNA contamination from other samples.

\section{RESULTS}

\section{Clinicopathologic Findings}

Of the 16 patients, 11 had lymph node metastases (Dukes' C) and 4 had no lymph node metastases (Dukes' B). No data were available regarding metastases in the remaining one patient. Twenty-seven of the 32 lesions (84\%) were of low grade, including one mucinous carcinoma, and 4 were of high grade. Furthermore, 5 of the 32 lesions were associated with tubular adenomas (Table 1).

The lesions in two patients were histologically similar (Patients 7 and 17). In Patient 7, each tumor was of low histologic grade with abundant mucin, goblet cells, and less-pleomorphic nuclei forming irregular glands (Figs. 1 and 2). Each contained foci of tubular adenoma. In Patient 17, each tumor was of low grade and had welldifferentiated glandular structures that had less-

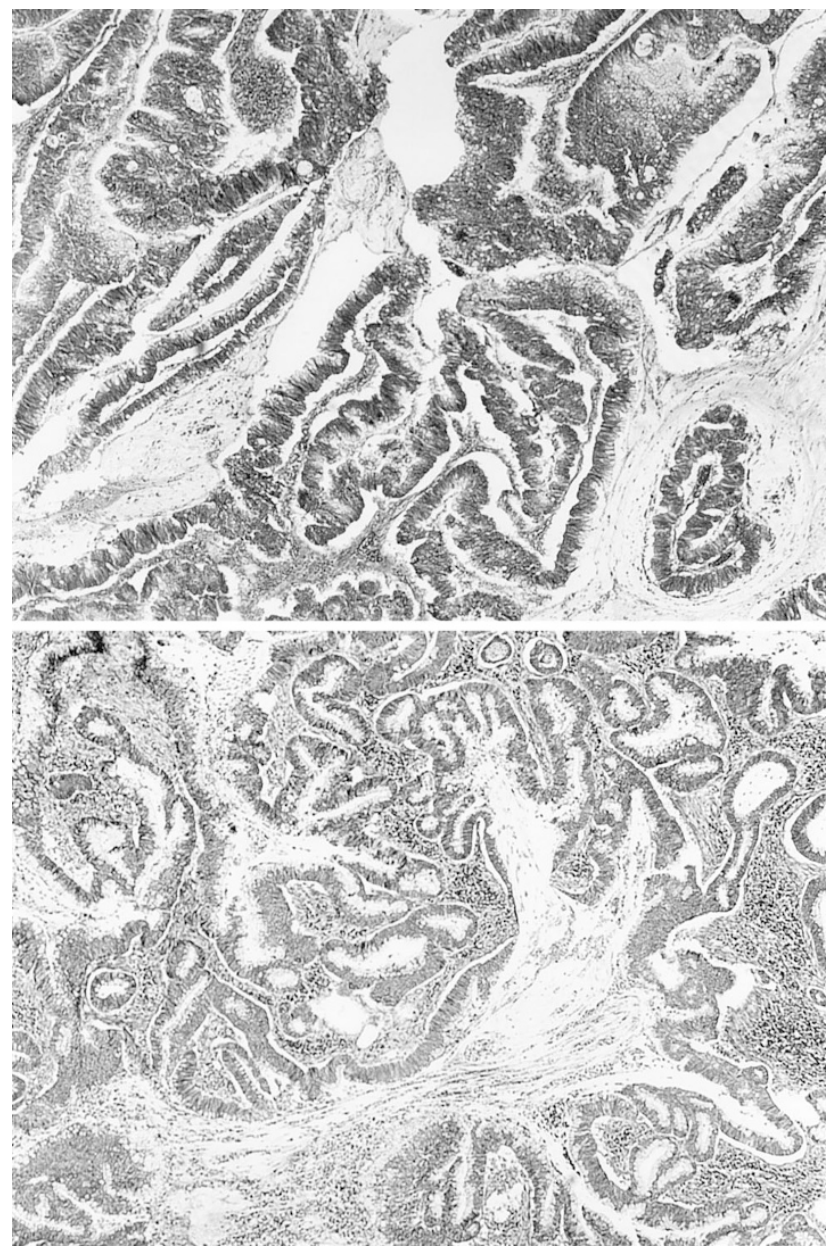

FIGURE 2. Patient 7. Adenocarcinoma in T1 (A) and T2 (B). These two tumors were histologically similar.

pleomorphic nuclei and that were located in the sigmoid colon. Two tumors were distinctly separated by $3.2-\mathrm{cm}$ intervals of normal bowel wall. The lesions in eight patients $(50 \%)$ were histologically dissimilar (Patients 14, 15, 19, 20, 21, 22, 23, and 25); in the remaining six patients (38\%), the multiple lesions were histologically similar in part (Patients 3, 6, 9, 13, 16, and 24).

\section{P53 Gene Alterations in Synchronous Colorectal Carcinomas}

Table 2 shows the characteristics of p53 gene mutations, together with the relevant immunohistochemical data in each case. All cases had p53 mutations in one or more of the multiple tumors. In nine patients with $p 53$ mutations in both tumors, individual lesions carried a different mutated codon of the $p 53$ gene. In the other seven patients, a $p 53$ mutation was found in one tumor but not in another. Hence, all of the cases examined showed heterogeneity in the location or the presence of $p 53$ mutation (representative results of SSCP and the corresponding DNA sequence analysis are shown in 
TABLE 2. Summary of the Analysis of Synchronous Colorectal Tumors for P53 Mutation

\begin{tabular}{|c|c|c|c|c|c|c|c|c|}
\hline \multirow{2}{*}{$\begin{array}{c}\text { Patient } \\
\text { No. }\end{array}$} & \multirow{2}{*}{$\begin{array}{c}\text { Tumor } \\
\text { No. }\end{array}$} & \multicolumn{5}{|c|}{ p53 Mutation } & \multirow{2}{*}{$\mathrm{LOH}$} & \multirow{2}{*}{ IHC } \\
\hline & & Exon & Codon & Base Change & Amino Acids & & & \\
\hline \multirow[t]{2}{*}{3} & $\mathrm{~T} 1$ & 5 & 182 & TGC-TAC & Cys-Tyr & transition & & $\begin{array}{c}\text { rrt; } \\
\text { col0 }\end{array}$ \\
\hline & $\mathrm{T} 2$ & 6 & 220 & TAT-TGT & Tyr-Cys & transition & & $2+$ \\
\hline \multirow[t]{2}{*}{6} & $\mathrm{~T} 1$ & $5-8$ & None & & & & & $1+$ \\
\hline & $\mathrm{T} 2$ & 5 & 178 & CAC-TAC & His-Tyr & transition & & $2+$ \\
\hline \multirow[t]{2}{*}{7} & $\mathrm{~T} 1$ & 5 & 175 & CGC-CAC & Arg-His & transition & & $2+$ \\
\hline & $\mathrm{T} 2$ & $5-8$ & None & & & & & 0 \\
\hline \multirow[t]{2}{*}{9} & $\mathrm{~T} 1$ & 7 & 244 & GGC-AGC & Gly-Ser & transition & + & $3+$ \\
\hline & $\mathrm{T} 2$ & 5 & 175 & CGC-CGT & Arg-Arg & silent & & $3+$ \\
\hline \multirow[t]{2}{*}{13} & $\mathrm{~T} 1$ & 7 & 240 & AGT-GGT & Ser-Gly & transition & & 0 \\
\hline & $\mathrm{T} 2$ & 7 & 248 & CGG-CAG & Arg-Gln & transition & & $3+$ \\
\hline \multirow[t]{2}{*}{14} & $\mathrm{~T} 1$ & 5 & 145 & CTG-CAG & Leu-Gln & transversion & + & $2+$ \\
\hline & $\mathrm{T} 2$ & & intron6 & g-a & & & & $1+$ \\
\hline \multirow[t]{4}{*}{15} & $\mathrm{~T} 1$ & 7 & 245 & GGC-AGC & Gly-Ser & transition & + & $3+$ \\
\hline & & 7 & 248 & CGG-CAG & Arg-Gln & transition & & \\
\hline & & 7 & 253 & ACC-ATC & Thr-Ile & transition & & \\
\hline & $\mathrm{T} 2$ & 7 & 246 & ATG-GTG & Met-Val & transition & & $3+$ \\
\hline \multirow[t]{2}{*}{16} & $\mathrm{~T} 1$ & $5-8$ & None & & & & & 0 \\
\hline & $\mathrm{T} 2$ & 7 & 241 & Deletion of C & Stop at codon 246 & & & 0 \\
\hline \multirow[t]{2}{*}{17} & $\mathrm{~T} 1$ & 7 & 245 & GGC-TGC & Gly-Cys & transversion & & $3+$ \\
\hline & $\mathrm{T} 2$ & 7 & 241 & TCC-TTC & Ser-Phe & transition & & $3+$ \\
\hline \multirow[t]{2}{*}{19} & $\mathrm{~T} 1$ & 7 & 245 & GGC-TGC & Gly-Cys & transversion & + & $3+$ \\
\hline & $\mathrm{T} 2$ & 6 & 220 & TAT-TGT & Tyr-Cys & transition & & $3+$ \\
\hline \multirow[t]{2}{*}{20} & $\mathrm{~T} 1$ & $5-8$ & None & & & & & 0 \\
\hline & $\mathrm{T} 2$ & 7 & 244 & GGC-AGC & Gly-Ser & transition & & $3+$ \\
\hline \multirow[t]{2}{*}{21} & $\mathrm{~T} 1$ & $5-8$ & None & & & & & 0 \\
\hline & $\mathrm{T} 2$ & 7 & 248 & CGG-CAG & Arg-Gln & transition & & $1+$ \\
\hline \multirow[t]{2}{*}{22} & $\mathrm{~T} 1$ & 7 & 258 & GAA-AAA & Glu-Lys & transition & & $3+$ \\
\hline & $\mathrm{T} 2$ & $5-8$ & None & & & & & $3+$ \\
\hline \multirow[t]{3}{*}{23} & $\mathrm{~T} 1$ & 5 & 176 & TGC-TAC & Cys-Tyr & transition & & $1+$ \\
\hline & & 7 & 259 & GAC-AAC & Asp-Asn & transition & & \\
\hline & $\mathrm{T} 2$ & 6 & 221 & GAG-GGG & Gln-Gly & transition & & 0 \\
\hline \multirow[t]{2}{*}{24} & $\mathrm{~T} 1$ & 6 & 220 & TAT-TGT & Tyr-Cys & transition & & $1+$ \\
\hline & $\mathrm{T} 2$ & 5 & 175 & CGC-CAC & Arg-His & transition & + & 0 \\
\hline \multirow[t]{2}{*}{25} & $\mathrm{~T} 1$ & & None & & & & & 0 \\
\hline & $\mathrm{T} 2$ & 6 & 200 & Deletion of $\mathrm{T}$ & Stop at codon 246 & & & 0 \\
\hline
\end{tabular}

LOH, loss of heterozygosity; IHC, immunohistochemistry; Cys, cystein; Tyr, tyrosine; His, histidine; Arg, arginine; Gly, glycine; Ser, serine; Gln, glutamine; Leu, leucine; Thr, threonine; Ile, isoleucine; Met, methionine; Val, valine; Phe, phenylalanine; Glu, glutamate; Lys, lysine; Asp, asparaginic acid; Asn, Asparagine; +, tumor with LOH; 0, negative tumors; $1+$, low expression ( 1 to $10 \%$ immunoreactive tumor cells); $2+$, moderate expression ( 10 to $50 \%$ immunoreactive tumor cells); and $3+$, high expression (50 to $100 \%$ immunoreactive tumor cells).

Figs. 3 and 4). In Patient 7, who had histologically similar synchronous lesions (Fig. 2), T1 showed a transition mutation at codon 175 (CGC-CAC). T2 did not have any mutation in exons 5 to 8 (Fig. 3). In Patient 17, who had histologically and immunohistochemically similar synchronous lesions, SSCP analysis revealed that $\mathrm{T} 1$ and $\mathrm{T} 2$ carried an identical mutated exon (exon 7), whereas DNA sequencing showed different locations of the mutations (GGCTGC at codon 245 in T1 and TCC-TTC at codon 241 in T2) (Fig. 4). Twenty-five of the 32 tumors had one or more $p 53$ mutations. Twenty-four of the $28 \mathrm{mu}$ tations $(86 \%)$ detected by sequencing resulted in missense errors, which led to a change in the amino acid sequence of p53 protein. Two nonsense mutations were due to the deletion of one base and resulted in frameshift mutations and the generation of a stop signal at codon 246. One intronic point mutation was also recognized. Mutations within introns may affect RNA splice sites and produce an abnormal p53 protein (27). Among the base substitutions, there was an extreme predominance of transitions. Twenty-one (88\%) missense mutations were transitions, whereas only 3 of 24 (13\%) were transversions. Fifteen of 21 transitions $(71 \%)$ were guanine:cytosine to adenine:thymine changes, of which 6 occurred at cytosine phosphate guanine sites. Codon 175 in exon 6 and codon 248 in exon 7 are known as "hot spots" in p53 mutations in human cancers, and the same mutation, guanine:cytosine to adenine:thymine, was found in five tumors from five patients. To distinguish between genetic alterations in the germline and somatic mutations, we compared our results with those in nonneoplastic tissues. The same exon in which the mutation was found in the tumor was analyzed by PCR-SSCP and sequenced in the non-neoplastic tissue. Because no genetic alterations could be detected in non-neoplastic tissues, all of the mutations found in the tumors must have been of somatic origin. In a comparison of the relative intensity of the mutant and wild-type SSCP bands, five tumors appeared to have a loss of heterozygosity (Table 2). We could not evaluate loss of het- 


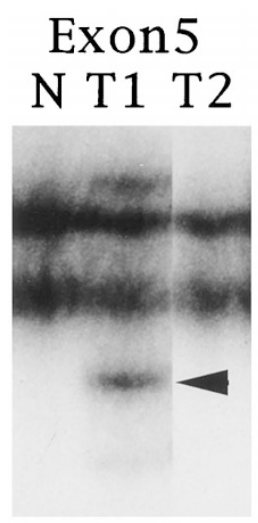

A

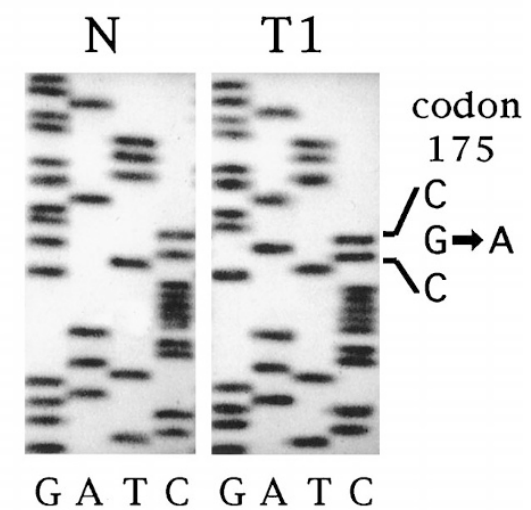

FIGURE 3. Patient 7. Single-strand conformation polymorphism showing a mobility shift (A) and sequencing (B) revealed that T1 carried a transition mutation (codon 175, CGC-CAC). N, normal tissue.

erozygosity in other tumor samples because of significant contamination by normal cellular DNA.

Immunohistochemical Analysis: Correlation with P53 Mutation by SSCP

Twenty-one of the 32 tumors (66\%) examined had positive staining for p53 (Table 2). Of the 21 carcinomas with positive staining, 19 (90\%) showed mutations by SSCP. In contrast, of the 11 carcinomas with negative staining, 6 (55\%) showed mutations by SSCP. The concordance between p53 nuclear reactivity and $p 53$ mutations using SSCP was $75 \%$ (Table 3). Two tumors that were negative in p53 immunohistochemistry revealed a mobility shift in SSCP and contained a one base-pair deletion resulting in a stop codon (codon 246). In 7 of the 16 patients, the p53 immunohistochemistry in synchronous lesions was concordant (Table 2).

\section{Correlation between P53 Alteration and Clinicopathologic Findings}

P53 mutations were found more often in leftsided tumors, including rectal tumors, than in

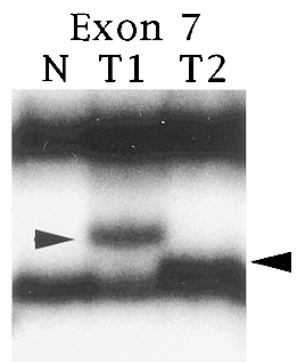

A

FIGURE 4. Patient 17. Single-strand conformation polymorphism (A) and sequencing (B) revealed that $\mathrm{T} 1$ and $\mathrm{T} 2$ both carried a transversion mutation in exon 7 (codon245, GGC-TGC, and codon241, TCC-TTC, respectively). $\mathrm{N}$, normal tissue.
TABLE 3. Relationship between Altered P53 Expression by Immunohistochemical Analysis and P53 Mutation by Single-Strand Conformation Polymorphism

\begin{tabular}{crrrrr}
\hline \multirow{2}{*}{ P53 Mutation } & Total & \multicolumn{4}{c}{ P53 Nuclear Reactivity } \\
\cline { 3 - 6 } & & 0 & $1+$ & $2+$ & $3+$ \\
\hline- & 7 & 5 & 1 & 0 & 1 \\
+ & 25 & 6 & 4 & 4 & 11 \\
\hline
\end{tabular}

0 , no nuclear reactivity; $1+$, sporadic nuclear reactivity (less than $10 \%$ of tumor nuclei); $2+$, focal nuclear reactivity (10 to $50 \%$ of tumor nuclei); $3+$, diffuse nuclear reactivity (50 to $100 \%$ of tumor nuclei); - , normal band; + , abnormal band by single-strand conformation polymorphism.

right-sided tumors, with a significant difference between right-sided tumors and rectal tumors $(P=$ .04). The frequency of p53 nuclear reactivity in right-sided tumors was significantly lower than that in left-sided tumors, including rectal tumors $(P<$ .05 , Fisher's exact test). The frequency of $p 53 \mathrm{mu}-$ tations in high-grade tumors was significantly lower than that in low-grade tumors $(P<.05$, Fisher's

\section{DISCUSSION}

Multiple tumors at many sites have been studied at a genetic level in many organs by several molecular techniques, including allelic deletions at chromosome-specific loci, viral integration analysis, flow cytometric analysis, and point mutation of specific genes, and the results have indicated that they were either monoclonal or multicentric.

With regard to the colon, however, the results regarding the cause of diverse lesions have not always been in agreement. Koness et al. (18) reported the discordance of $p 53$ and K-ras mutations among individual lesions in the same patient, strongly suggesting that the great majority of synchronous colorectal carcinomas arise as independent neoplasms. In contrast, another study that used flow cytometric

TABLE 4. Relationship among P53 Expression, P53 Mutations, and Pathologic Characteristics

\begin{tabular}{|c|c|c|c|}
\hline & \multirow{2}{*}{$\begin{array}{l}\text { No. of } \\
\text { Cases }\end{array}$} & \multicolumn{2}{|c|}{ Frequency of Cases (\%) } \\
\hline & & $\begin{array}{c}\text { P53 } \\
\text { Expression }\end{array}$ & $\begin{array}{c}\text { P53 } \\
\text { Mutation }\end{array}$ \\
\hline \multicolumn{4}{|l|}{ Tumor site } \\
\hline Right side & 7 & $1(14 \%)^{b}$ & $3(43)^{c}$ \\
\hline Left side & 14 & $12(86)$ & $10(71)$ \\
\hline Rectum & 11 & $10(91)$ & $10(91)$ \\
\hline \multicolumn{4}{|c|}{ Histologic differentiation } \\
\hline Low grade & $28^{a}$ & $19(68)$ & $24(86)^{d}$ \\
\hline High grade & 4 & $2(50)$ & $1(25)$ \\
\hline \multicolumn{4}{|c|}{$\begin{array}{l}{ }^{a} \text { Including one mucinous carcinoma. } \\
{ }^{b} \text { Significant difference between right-sided tumors and left-sided tu- } \\
\text { ors, including rectal tumors ( } p<.05 \text {, by Fisher's exact test). } \\
{ }^{c} \text { Significant difference between right-sided tumors and rectal tumors } \\
=.04 \text {, by Fisher's exact test). } \\
{ }^{d} \text { Significant difference between high-grade tumors and low-grade tu- } \\
\text { ors }(p<.05 \text {, by Fisher's exact test). }\end{array}$} \\
\hline
\end{tabular}
mors ( $p<.05$, by Fisher's exact test). exact test) (Table 4).

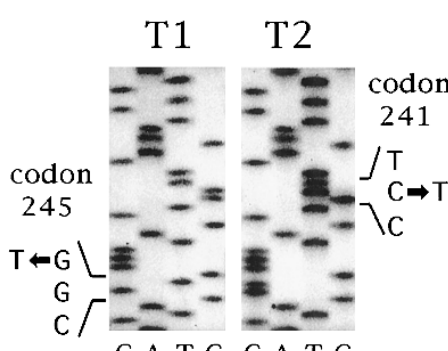

G A T C G A T C
-strand conformation polymorphism
GGC-TGC, and codon241, TCC-TTC 
analysis noted that 3 of 10 patients with colorectal carcinomas had aneuploid tumors with identical DNA ploidy, suggesting that multiple primary carcinomas may, in some cases, be clonally related (19).

All of the cases examined in this study showed heterogeneity of the location or presence of $p 53$ mutations. Two cases showed a markedly similar histology, along with a similar immunohistochemistry in one case, as well as a discrepancy in $p 53$ mutation. The results of this investigation provide some support for the idea that most synchronous colorectal carcinomas are multicentric rather than monoclonal in origin. However, it is still possible that some of the synchronous colorectal carcinomas have a common origin, but tumor cells might migrate to other sites before the development of p53 mutations, resulting in primary and secondary sites displaying independent $p 53$ mutations.

Delattre et al. (28) speculated that proximal and distal colon carcinomas might differ with regard to the genetic mechanism of their initiation and/or progression, because distal tumors show allelic losses more than twice as often as proximal tumors do. Moreover, Jernvall et al. (29) indicated that mutations in the conserved regions of the $p 53$ gene accumulate in distal but not in proximal tumors. In our limited series of tumors, we confirmed the higher frequency of $p 53$ mutations in left-sided (71\%) and rectal $(91 \%)$ carcinomas than in rightsided $(43 \%)$ carcinomas (Table 4). Immunohistochemically, six of the seven right-sided tumors had negative staining for p53 protein. In addition, only one (Patient 3, T2) of the seven proximal tumors had a transition mutation in the nonconserved area. Moreover, in three of the five patients with both proximal and distal tumors, the proximal tumors had no mutations whereas the distal tumors had a mutation in the conserved regions of the gene. With regard to tumor location in synchronous colorectal carcinomas, the molecular mechanism of colorectal carcinogenesis may differ between rightand left-sided tumors, and the $p 53$ genetic pathway of individual lesions may be fundamentally the same as that of sporadic colorectal carcinomas.

Point mutations of the p53 tumor suppressor gene have been reported in approximately $50 \%$ of colorectal carcinomas (30). Almost all of these mutations have been transitions, resulting in single base-pair changes (31). G:C to A:T transitions compose approximately 60 to $80 \%$ of colorectal tumor mutations, and most of them occur at cytosine phosphate guanine dinucleotides, as shown by previous studies $(2,30-33)$. Moreover, most of these mutations are localized in four regions of the protein (residues 117-142, 171-181, 234-258, and 270286), which are highly conserved among several different species (5). There are at least three mutation hot spots, affecting residues 175, 248, and 273 (34). In the current study, p53 mutations were scattered in exons 5 to 7 and were not clustered within hot spots. Only 6 of the 24 missense mutations showed a G:C to A:T transition at cytosine phosphate guanine dinucleotides (25\%). These results regarding p53 mutation may reflect the limited number of samples examined in this study. Other reasons for these differences include the possibility of differences in environmental exposure or inherited characteristics among the populations, based on previous reports of different proportions of the p53 mutation spectrum $(2,35-37)$.

We also performed p53 immunohistochemical analysis on all of the tumors in this series. The two techniques gave concordant results in $75 \%$ of the tumors. Esrig et al. (38) and many other investigators have presented several possible reasons for the discrepancy between $p 53$ gene mutations by SSCP and p53 expression by immunohistochemistry. In this study, two cases were immunohistochemically positive and SSCP negative ( $6 \%$ of the tumors). If the proportion of cells containing the mutation is low or if mutations occur outside the regions examined (exons 5 to 8), this could explain cases in which immunohistochemistry was positive but no mutation was detected $(8,38)$. Conversely, six cases were immunohistochemically negative and SSCP positive (19\%). P53 mutations could be identified by DNA analysis, whereas no p53 is detected immunohistochemically if the mutation produces a stop signal or a large rearrangement or deletion that prevents expression of the protein. The muta tion may also produce a protein with a very short half-life that cannot be detected immunohistochemically (27). Exon 5 resides closest to the denaturation-resistant epitope between amino acids 32 and 79 of the p53 protein. Therefore, mutations at exon 5 may alter the conformation of the p53 protein, making it more difficult to detect by immunohistochemistry using the monoclonal antibody PAb1801. Moreover, a p53 protein mutated at exon 6 may be degraded more rapidly, resulting in a low-intensity heterogeneous staining pattern (38).

In conclusion, these results show that synchronous colorectal carcinomas reveal a variety of mutations and have different patterns of genetic changes at separate sites. This suggests the independent development of synchronous colorectal carcinomas that are genetically distinguishable.

Acknowledgments: The surgical specimens and clinical data reported here were obtained from the following institutes: Kyushu University Hospital, Wakamatsu Public Hospital, Kimura Hospital, Ku- 
roki Hospital, and Nougata Central Hospital. We thank Tomoko Tahira, Akari Suzuki, Yoji Kukita (Division of Genome Analysis, Institute of Genetic Information, Kyushu University), Yoichi Hachitanda (Division of Pathology, Clinical Laboratory, Kitakyushu Municipal Medical Center), and Takashi Utsunomiya (National Kyushu Medical Center) for their laboratory help and advice.

\section{REFERENCES}

1. Moertel CG, Bargen JA, Dockerty MB. Multiple carcinomas of the large intestine: a review of the literature and a study of 261 cases. Gastroenterology 1958;34:85-98.

2. Greenblatt MS, Bennett WP, Hollstein M, Harris CC. Mutations in the p53 tumor suppressor gene: clues to cancer etiology and molecular pathogenesis. Cancer Res 1994;54: 4855-78.

3. Chung KY, Mukhopadhyay T, Kim J, Casson A, Ro JY, Goepfert $\mathrm{H}$, et al. Discordant p53 gene mutations in primary head and neck cancers and corresponding second primary cancers of the upper aerodigestive tract. Cancer Res 1993; 53:1676-83.

4. Yang HK, Linnoila RI, Conrad NK, Krasna MJ, Aisner SC, Johnson BE, et al. TP53 and RAS mutations in metachronous tumors from patients with cancer of the upper aerodigestive tract. Int J Cancer 1995;64:229-33.

5. Sozzi G, Miozzo M, Pastorino U, Pilotti S, Donghi R, Giarola $\mathrm{M}$, et al. Genetic evidence for an independent origin of multiple preneoplastic and neoplastic lung lesions. Cancer Res 1995;55:135-40.

6. Kang GH, Kim CJ, Kim WH, Kang YK, Kim HO, Kim YI. Genetic evidence for the multicentric origin of synchronous multiple gastric carcinoma. Lab Invest 1997;407-17.

7. Sakamoto M, Hirohashi S, Tsuda H, Shimosato Y, Makuuchi M, Hosoda Y. Multicentric independent development of hepatocellular carcinoma revealed by analysis of hepatitis B virus integration pattern. Am J Surg Pathol 1989;13:1064-7.

8. Sidransky D, Frost P, Von EA, Oyasu R, Preisinger AC, Vogelstein B. Clonal origin bladder cancer. N Engl J Med 1992; 326:737-40.

9. Lunec J, Challen C, Wright C, Mellon K, Neal DE. C-erbB-2 amplification and identical p53 mutations in concomitant transitional carcinomas of renal pelvis and urinary bladder. Lancet 1992;339:439-40.

10. Kupryjanczyk J, Thor AD, Beauchamp R, Poremba C, Scully RE, Yandell DW. Ovarian, peritoneal, and endometrial serous carcinoma: clonal origin of multifocal disease. Mod Pathol 1996;9:166-73.

11. Mok CH, Tsao SW, Knapp RC, Fishbaugh PM, Lau CC. Unifocal origin of advanced human epithelial ovarian cancers. Cancer Res 1992;52:5119-22.

12. Smit VT, Fleuren GJ, van Houwelingen JC, Zegveld ST, Kuipers-Dijkshoorn NJ, Cornelisse CJ. Flow cytometric DNAploidy analysis of synchronously occurring multiple malignant tumors of the female genital tract. Cancer 1990;66: 1843-9.

13. Noguchi S, Aihara $T$, Koyama $H$, Motomura $K$, Inaji $H$, Imaoka S. Discrimination between multicentric and multifocal carcinomas of the breast through clonal analysis. Cancer 1994;74:872-7.

14. Goto K, Konomoto T, Hayashi K, Kinukawa N, Naito S, Kumazawa J, et al. P53 mutations in multiple urothelial carcinomas: a molecular analysis of the development of multiple carcinomas. Mod Pathol 1997;10:428-37.

15. Oda T, Tsuda H, Scarpa A, Sakamoto M, Hirohashi S. Mutation pattern of the p53 gene as a diagnostic marker for multiple hepatocellular carcinoma. Cancer Res 1992;52:3674-8.

16. Tsuda H, Oda T, Sakamoto M, Hirohashi S. Different pattern of chromosomal allele loss in multiple hepatocellular carcinomas as evidence of their multifocal origin. Cancer Res 1992;52:1504-9.

17. Greenstein AJ, Slater G, Heimann TM, Sachar DB, Aufses AH Jr. A comparison of multiple synchronous colorectal cancer in ulcerative colitis, familial polyposis coli, and de novo cancer. Ann Surg 1986;203:123-8.

18. Koness RJ, King TC, Schechter S, McLean SF, Lodowsky C, Wanebo HJ. Synchronous colon carcinomas: moleculargenetic evidence for multicentricity. Ann Surg Oncol 1996;3: $136-43$.

19. Schwartz D, Banner BF, Roseman DL, Coon JS. Origin of multiple "primary" colon carcinomas: a retrospective flow cytometric study. Cancer 1986;58:2082-8.

20. Vasen HFA, Mecklin J-P, Khan PM, Lynch HT. The international collaborative group on hereditary non-polyposis colorectal cancer (ICG-HNPCC). Dis Colon Rectum 1991;34:424-5.

21. Large intestine. In: Jass JR, Sobin LH, editors. Histological typing of intestinal tumours. 2nd ed. Berlin: Springer-Verlag; 1989. pp. 29-40.

22. Turnbull RJ, Kyle K, Watson FR, Spratt J. Cancer of the colon: the influence of the no-touch isolation technic on survival rates. Ann Surg 1967;166:420-7.

23. Goelz SE, Hamilton SR, Vogelstein B. Purification of DNA from formaldehyde fixed and paraffin embedded human tissue. Biochem Biophys Res Commun 1985;130:118-26.

24. Hayashi K, Kukita Y, Inazuka M, Tahira T. Single-strand conformation polymorphism analysis. In: Cotton RGH, Edkins E, Forrest S, editors. Mutation detection. Oxford: Oxford University Press; 1997. pp. 7-17.

25. Orita M, Suzuki Y, Sekiya T, Hayashi K. Rapid and sensitive detection of point mutations and DNA polymorphisms using the polymerase chain reaction. Genomics 1989;5:874-9.

26. Suzuki Y, Sekiya T, Hayashi K. Allele-specific polymerase chain reaction: a method for amplification and sequence determination of a single component among a mixture of sequence variants. Anal Biochem 1991;192:82-4.

27. Dunn JM, Hastrich DJ, Newcomb P, Webb JC, Maitland NJ, Farndon JR. Correlation between p53 mutations and antibody staining in breast carcinoma. Br J Surg 1993;80:1410-2.

28. Delattre O, Olschwang S, Law DJ, Melot T, Remvikos Y, Salmon RJ, et al. Multiple genetic alterations in distal and proximal colorectal cancer. Lancet 1989;2:353-6.

29. Jernvall $P$, Makinen M, Karttunen T, Makela J, Vihko P. Conserved region mutations of the p53 gene are concentrated in distal colorectal cancers. Int J Cancer 1997;74:97101.

30. Hollstein M, Sidransky D, Vogelstein B, Harris CC. P53 mutations in human cancers. Science 1991;253:49-53.

31. Baker SJ, Preisinger AC, Jessup JM, Paraskeva C, Markowitz $\mathrm{S}$, Willson JK, et al. P53 gene mutations occur in combination with $17 \mathrm{p}$ allelic deletions as late events in colorectal tumorigenesis. Cancer Res 1990;50:7717-22.

32. Nigro JM, Baker SJ, Preisinger AC, Jessup JM, Hostetter R, Cleary K, et al. Mutations in the p53 gene occur in diverse human tumour types. Nature 1989;342:705-8.

33. Cunningham J, Lust JA, Schaid DJ, Bren GD, Carpenter HA, Rizza E, et al. Expression of p53 and 17p allelic loss in colorectal carcinoma. Cancer Res 1992;52:1974-80.

34. Levine AJ, Momand J, Finlay CA. The p53 tumour suppressor gene. Nature 1991;351:453-6.

35. Kikuchi YR, Konishi M, Ito S, Seki M, Tanaka K, Maeda Y, et al. Genetic changes of both p53 alleles associated with the conversion from colorectal adenoma to early carcinoma in familial adenomatous polyposis and non-familial adenoma- 
tous polyposis patients. Cancer Res 1992;52:3965-71.

36. Lothe RA, Fossli T, Danielsen HE, Stenwig AE, Nesland JM, Gallie B, et al. Molecular genetic studies of tumor suppressor gene regions on chromosomes 13 and 17 in colorectal tumors. J Natl Cancer Inst 1992;84:1100-8.

37. Wu AH, Paganini HA, Ross RK, Henderson BE. Alcohol, phys- ical activity and other risk factors for colorectal cancer: a prospective study. Br J Cancer 1987;55:687-94.

38. Esrig D, Spruck CH III, Nichols PW, Chaiwun B, Steven K, Groshen S, et al. P53 nuclear protein accumulation correlates with mutations in the p53 gene, tumor grade, and stage in bladder cancer. Am J Pathol 1993;143:1389-97.

\section{Book Review}

\section{Sternberg SS (ed): Diagnostic Surgical Pathol- ogy, 3rd Ed, Vols 1 \& 2, 2445 pp, Philadel- phia, Lippincott Williams \& Wilkins, 1999 (\$299).}

Looking at the third edition of the book, known as The Sternberg, I could not stop thinking of a sentence of Andre Gide that I transcribed into my notebook many years ago: "The problem is not how to succeed, but how to last." Anybody could write a book and get it published even, but to get it through more than one edition, "hoc opus, hic labor est" (Aen. VII, 129). Needless to say, kudos are in order.

Several explanations could be offered to account for the success of this book. When it appeared, it was the first multiauthored well-done American textbook of surgical pathology. Dr. Sternberg is a master editor and has assembled a stellar team of coeditors and contributors, who lend authority to their writing and inspire confidence among the readers. The book is practice oriented, and the coverage of various aspects of surgical pathology is consistently of the highest caliber.

Those who read book reviews in Modern $\mathrm{Pa}$ thology will remember that I have praised and endorsed unconditionally the two previous editions of Dr. Sternberg's book. It would probably suffice to say now that the third edition is not only as good as the previous ones but is actually much better. All chapters were significantly updated, and many were dramatically redesigned. Most photographs are now in color. Current views on common forms of cancer, such as carcinoma of the breast and prostate or soft tissue sarcomas, are presented in a balanced form, with cogent argumentation for the changes that are being introduced by competing groups of pathologists. One could argue whether lymphomas deserve only 70 pages, but one must admit that this chapter came out as an exemplary effort to translate the language of lymphomaniacs into regular pathologese. On the other hand, one could ask whether some diseases are covered too extensively (e.g., does lymphomatoid granulomatosis deserve two and a half pages; does nevoid basal cell carcinoma syndrome need a half-page line drawing; do some electron microphotographs really need to be printed in the large format?). Such comments probably should be solicited from readers, and I suggest that they be sent to the editor and his colleagues for consideration as they plan the next edition. My own comments and "critical remarks" I have already sent to Dr. Sternberg, with congratulations and a personal thank you note for this truly outstanding book, which, like good wine, keeps improving with time.

To summarize, the third edition of Sternberg is a modern, up-to-date textbook of surgical pathology that deserves to be on the bookshelf of all practicing pathologists and their departmental and hospital libraries.

\section{Ivan Damjanov \\ University of Kansas School of Medicine \\ Kansas City, Kansas}

